\title{
Evaluation of a Legume-Derived Protein Hydrolysate to Mitigate Iron Deficiency in Plants
}

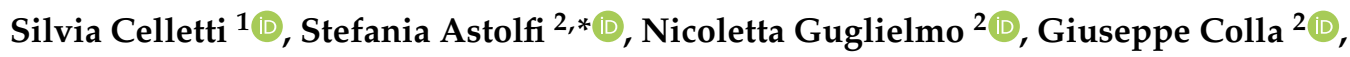 \\ Stefano Cesco $^{1}$ and Tanja Mimmo ${ }^{1,3}{ }^{\mathbb{D}}$ \\ 1 Faculty of Science and Technology, Free University of Bozen-Bolzano, 39100 Bolzano, Italy; \\ silvia.celletti@unibz.it (S.C.); stefano.cesco@unibz.it (S.C.); tanja.mimmo@unibz.it (T.M.) \\ 2 Department of Agricultural and Forestry Sciences, University of Tuscia, 01100 Viterbo, Italy; \\ nicolettaguglielmo@outlook.com (N.G.); giucolla@unitus.it (G.C.) \\ 3 Competence Centre for Plant Health, Free University of Bozen-Bolzano, 39100 Bolzano, Italy \\ * Correspondence: sastolfi@unitus.it; Tel.: +39-0761-357337
}

Received: 12 November 2020; Accepted: 8 December 2020; Published: 10 December 2020

\begin{abstract}
Biostimulants play an important role in the development of management practices able to reach adequate productivity to meet the food demand of a growing world population, while following a sustainable agriculture model. This work aims to evaluate the effect of a protein hydrolysate derived from legume seeds by enzymatic hydrolysis on plant growth and also to verify its ability to mitigate Fe deficiency, a widespread problem significantly limiting plant growth and crop productivity. Experiments were performed with tomato (Solanum lycopersicum L.-cv. AKRAI F1) and cucumber (Cucumis sativus L.-cv. EKRON F1). The plants were grown hydroponically under adequate or limited Fe supply. Changes in shoot and root fresh weight, leaf relative chlorophyll content and the accumulation of macro- and microelements in shoots and roots were measured. Plant ability to cope with Fe deficiency was measured by evaluating the activity of root $\mathrm{Fe}^{3+}$-chelate reductase. Our results indicate that the foliar treatments with the protein hydrolysate did not significantly affect growth parameters when plants were grown in full nutrient solution. However, the biostimulant was able to improve the growth performance of Fe-deficient plants. Therefore, the protein hydrolysate can be a powerful tool to stimulate crop growth under Fe-deficient environments, leading to reduced fertilizer inputs with related environmental and economic benefits.
\end{abstract}

Keywords: biostimulant; cucumber; iron; protein hydrolysate; strategy I; tomato

\section{Introduction}

Iron $(\mathrm{Fe})$ is one of the micronutrients which is responsible for the quality and quantity of crop yields and, therefore, its deficiency significantly impacts agricultural production at the global level [1,2]. In fact, being crucial for the proper functioning of metabolic processes related to electron transport such as respiration and photosynthesis as well as those connected with the biosynthesis of fundamental molecules, e.g., chlorophyll [3,4], Fe plays a crucial role in the whole metabolism (anabolic and catabolic) of plants. When Fe availability in the growth medium is not adequate, crops display typical visual symptoms such as interveinal leaf chlorosis of the younger leaves and stunted development of the whole plant, making the diagnosis of the nutritional disorder rather easy to make [5]. At the cellular level, instead, the Fe shortage induces serious imbalances in the ultrastructure and functionality of chloroplasts, as $90 \%$ of leaf-Fe is present in chloroplasts [6,7], with relevant implications for all the metabolic pathways carried out in these organelles.

The Fe content of soils is high, being the fourth element in Earth's crust in percentage. Therefore, the widespread limited availability of Fe for plant nutrition is not related to its low absolute soil 
content, but rather to its extremely low solubility. In particular, Fe deficiency is a typical feature of alkaline soils [5]. Considering that these soils represent about $25 \%$ of Earth's surface [8], from an agronomical point of view, the consistency of this problem is evident. To worsen the context, there is then the buffer capacity of these soils which, by influencing the $\mathrm{pH}$ at the root surface, can depress the functionality of the mechanisms underlying nutrient acquisition by the crops $[9,10]$. Therefore, it is clear why the management of plant Fe nutrition has been the focus of great attention in recent decades. In this context, it should be mentioned that specific targets such as (i) the enhanced plant availability of the soil endogenous Fe forms, (ii) the higher use efficiency of the exogenous Fe sources (fertilizers) supplied foliarly or to the soil and/or (iii) the more efficient metabolic use of the metal acquired by crops have been addressed by applying different approaches. Considering the prediction of a constant increase in population density as well as in the food demand in the near future, concurrently with the decrease in the arable land surface, it is clear how urgent it is to identify comprehensive answers (i.e., novel agronomic practices) to the problem of plant nutrition management. In this regard, it should be necessary to privilege strategies that also meet the great current challenge of agriculture to protect the environment. In this respect and specifically in a context of more sustainable agriculture, plant biostimulants can be surely considered one of the valid tools. In fact, they are defined novel "environmental-friendly" natural products capable of contributing considerably to the achievement of high yields and good-quality products. This group of natural products includes both substances/molecules and microorganisms that, even if applied to soil or directly to the plants in a very small quantity, allow crops to enhance the efficiency of the whole nutrition acquisition process, the tolerance levels to abiotic stresses and/or the expression of the quality traits of crop products [11] and references therein. These beneficial effects of biostimulants are generally ascribed to an indirect effect on soil properties and microbial activities at the rhizosphere (which, in turn, promote plant growth and development) or to a direct action on the plant traits contributing to its growth [12]. With respect to the latter, it has been reported that some categories of biostimulants could be able to improve plant nutritional status by increasing the efficiency of the nutrient acquisition process, regardless of the nutrients' levels directly supplied with the biostimulant [reviewed in 11].

This action could be mainly ascribed to three major groups of substances, including humic substances [13], hormone-containing products [14] and protein hydrolysates [15]. With respect to the latter, they are nitrogen $(\mathrm{N})$-containing compounds obtained by thermal, chemical and/or enzymatic hydrolysis of various raw materials of plant or animal origin. Vegetal-derived protein hydrolysates have been proven to be very effective in enhancing crop performances through the increase in plant nutrient availability, nutrient uptake and metabolic use, abiotic stress resistance and the expression of crop quality traits $[16,17]$.

The aim of this work is to evaluate the effect of a legume-derived protein hydrolysate on plant growth and development and to verify the biostimulant's ability to mitigate the effects of Fe deficiency. To this purpose, two different crops (tomato (Solanum lycopersicum L. - cv. AKRAI F1) and cucumber (Cucumis sativus L.- cv. EKRON F1)) were chosen as model plants because of their economic and social importance. Tomato is one of the most popular vegetables in the world and the world's third largest vegetable crop after potato and onion. The leading tomato-producing countries in the world are China, India, USA, Turkey, Egypt, Iran, Italy, Spain and Brazil, with a global cultivated area of about 4.73 million hectares and a production of 163.96 million tons (FAO, 2016). Both tomatoes and tomato-based products (tomato sauce and juice) have great nutritional value, being rich in several nutrients, including vitamins [18].

Moreover, cucumber is an important vegetable crop and represents an important food for the human diet, with a wide cultivation area and a market area mostly including countries such as Greece, Holland, Finland and Germany [19].

The increased consumption of both products has triggered a significant acreage extension for many countries worldwide. However, both tomato and cucumber cultivation urgently need major 
transformation, including overall improvement of the production system through varietal renewal, but also the development of new agronomic practices, including fertilizer management.

During the last 40 years, agricultural production has nearly doubled thanks to the application of large doses of fertilizers, the use of increasingly high-yielding varieties and the intensive use of water and pesticides [20]. Such intensive cropping systems have, in some cases, severely compromised the soil quality and fertility, resulting in a series of critical issues such as limited nutrients' content, soil acidification, soil salinization, drop in soil biological activity and a significant depletion of the organic matter content. In this context, the current challenges of food safety and security, concurrently with the progressive decrease in the agricultural land surface, urge identifying novel agronomic practices allowing for quali-quantitatively improving primary productions in a context of increasing agricultural sustainability. In this respect, in recent years, the research interest toward the application of biostimulants in agriculture has been clearly intensified. Among biostimulants, protein hydrolysates are particularly interesting for their demonstrated ability to modulate the molecular and physiological processes that promote plant growth, favor increased yield and alleviate the impact of abiotic stress on crops [21].

The purpose of this study is thus to verify whether foliar application of the protein hydrolysate could improve growth parameters (expressed as shoot and root fresh weight and relative chlorophyll content) as well as nutrient accumulation in both shoot and root tissues of tomato and cucumber plants. Ultimately, the combination of limited Fe supply and biostimulant application will allow further evaluating the effect of the protein hydrolysate on the plant's ability to cope with Fe deficiency, by analyzing changes in the activity of root $\mathrm{Fe}^{3+}$-chelate reductase, since both crops rely on an $\mathrm{Fe}^{3+}$ reduction-based mechanism for micronutrient acquisition [22].

\section{Materials and Methods}

\subsection{Plant Growth Conditions}

Tomato (Solanum lycopersicum L.—cv. AKRAI F1) and cucumber (Cucumis satious L.-cv. EKRON F1) seeds were germinated on perlite soaked with distilled water in the dark at $24^{\circ} \mathrm{C}$ for 4 days. Half of the homogeneous seedlings were transferred in $2 \mathrm{~L}$ plastic pots ( 6 seedlings/pot), filled with a continuously aerated full nutrient solution (NS) [23] (control, C), having the following composition: $(\mathrm{mM}) 2 \mathrm{Ca}\left(\mathrm{NO}_{3}\right)_{2}$, $0.7 \mathrm{~K}_{2} \mathrm{SO}_{4}, 0.1 \mathrm{KH}_{2} \mathrm{PO}_{4}, 0.1 \mathrm{KCl}$ and $0.5 \mathrm{MgSO}_{4}$; and $(\mu \mathrm{M}) 10 \mathrm{H}_{3} \mathrm{BO}_{3}, 0.5 \mathrm{MnSO}_{4}, 0.2 \mathrm{CuSO}_{4}, 0.5 \mathrm{ZnSO}_{4}$, $0.01\left(\mathrm{NH}_{4}\right)_{6} \mathrm{Mo}_{7} \mathrm{O}_{24}$ and $40 \mathrm{Fe}^{3+}$-EDTA. The other half of the homogeneous seedlings were transferred to the same $2 \mathrm{~L}$ pots ( 6 seedlings/pot), containing the same full NS, but with a lower Fe concentration $\left(4 \mu \mathrm{M} \mathrm{Fe}^{3+}\right.$-EDTA, F).

Plants were grown hydroponically in a climate chamber with a day/night cycle of 16/8 h, temperature regime of $27 / 20^{\circ} \mathrm{C}$, light intensity of about $200 \mu \mathrm{mol} \mathrm{m} \mathrm{m}^{-2} \mathrm{~s}^{-1}$ at the plant level and relative humidity of $70 \%$. The NS was continuously aerated and changed every three days.

After 8 and 15 days, half of the plants of each condition (C, control, and F, Fe-deficient condition) were foliarly treated with a protein hydrolysate solution by means of a spray bottle applying $300 \mathrm{mg}$ per plant of hydrolysate at the concentration of $3 \mathrm{~mL} \mathrm{~L}^{-1}$. The commercial legume seed-based hydrolysate Trainer $^{\circledR}$ (Italpollina S.p.A. Rivoli Veronese, Italy) had a total $\mathrm{N}$ concentration of $50 \mathrm{~g} \mathrm{~kg}^{-1}$ containing free amino acids and soluble peptides [21]. The hydrolysate contained the following amino acids: $\left(\mathrm{g} \mathrm{kg}^{-1}\right.$ ) Ala (12), Arg (18), Asp (34), Cys (3), Glu (54), Gly (12), His (8), Ile (13), Leu (22), Lys (18), Met (4), Phe (15), Pro (15), Thr (11), Trp (3), Tyr (11) and Val (14).

Cucumber and tomato plants were harvested after 17 and 22 days from sowing, respectively. Shoots and roots were separated, and their fresh biomass was determined by weighing.

\subsection{Determination of Relative Chlorophyll Content}

At harvest (17 and 22 days after sowing for cucumber and tomato, respectively), the relative chlorophyll content per unit area was measured on the youngest fully expanded leaves of each plant 
by using a portable chlorophyll meter SPAD-502 (Konica Minolta, Osaka, Japan), and recorded values were expressed as SPAD units.

\subsection{Determination of Root $\mathrm{Fe}^{3+}$-Chelate Reductase Activity}

The $\mathrm{Fe}^{3+}$-chelate reductase activity of tomato and cucumber roots was assayed colorimetrically, using bathophenantrolinedisulfonate (BPDS) reagent [24,25]. Briefly, roots of intact plants were carefully rinsed in deionized water and incubated in darkness at room temperature in a continuously aerated assay solution, with the following composition: $0.5 \mathrm{mM} \mathrm{CaSO}_{4}, 10 \mathrm{mM}$ MES-KOH (pH 5.5), $0.25 \mathrm{mM} \mathrm{Fe}^{3+}$-EDTA and $0.6 \mathrm{mM}$ BPDS. After $20 \mathrm{~min}$, the absorbance of the assay solution was determined at $535 \mathrm{~nm}$ with a spectrophotometer [26]. The reduced Fe was calculated on the basis of the concentration of the $\mathrm{Fe}^{2+}-\mathrm{BPDS}_{3}$ complex, using the molar extinction coefficient of $22.1 \mathrm{mM}^{-1} \mathrm{~cm}^{-1}$, and was expressed in $\mu$ mol Fe reduced $\mathrm{h}^{-1} \mathrm{~g}^{-1}$ root FW.

\subsection{Determination of Macro- and Micronutrients}

Shoots and roots of both plant species were dried at $60{ }^{\circ} \mathrm{C}$ until constant weight was reached and ball-milled (Mixer Mill, MM 400, Retsch, Italy) to obtain a homogeneous powder. Samples were then acid-digested with ultra-pure $\mathrm{HNO}_{3}\left(650 \mathrm{~mL} \mathrm{~L}^{-1}\right.$; Carlo Erba, Milano, Italy) using a Single Reaction Chamber Microwave (SRC, UltraWAVE, Milestone Inc, Shelton, CT, USA). Subsequently, mineralized samples were filtered and element concentrations were determined by ICP-OES (Arcos Ametek, Spectro, Germany), using tomato leaves (SRM 1573a) and spinach leaves (SRM 1570a) as external certified reference materials.

\subsection{Statistical Analysis}

Each reported value represents the mean \pm standard error (SE) of three independent experiments (biological replicates) run in triplicate (technical replicates). Statistical analysis was carried out using SigmaPlot Version 12.2 on Windows 1064 bit. Statistical significance was tested by one-way ANOVA analysis with the Student-Newman-Keuls post hoc test at ${ }^{*} p<0.05,{ }^{* *} p<0.01$ and ${ }^{* * *} p<0.001$. Principle component analysis (PCA) was performed with PAST Version 4.03 for Windows.

\section{Results}

\subsection{Effect of Growth Condition on Growth Parameters of Tomato and Cucumber Plants}

At harvest (i.e., 22 days after sowing), tomato plants showed the same developmental stage in terms of leaf number, independently from the nutrient supply and biostimulant application (C: control; CB: control treated with the protein hydrolysate; F: Fe-deficient; and FB: Fe-deficient treated with the protein hydrolysate) (Figure 1A).

The biomass of tomato plants exposed to Fe deficiency, evaluated in terms of shoot and root fresh weight $(\mathrm{FW})$, did not show statistically significant variations compared to the control condition (F vs. C, Figure 1B). However, when F plants were supplied with the protein hydrolysate (FB condition), the shoot biomass doubled, but not the root biomass, which remained unchanged, compared to the control (FB vs. C). Furthermore, FB plants increased both shoot and root biomass by more than $50 \%$ when compared to F plants (Figure 1B). On the other hand, the protein hydrolysate added to plants grown in a full NS (CB vs. C) had notable diverse effects on the biomass accumulation, yet without statistical differences: biostimulants increased the shoot biomass by approximately $60 \%$ and reduced the root biomass by $20 \%$ with respect to $C$ plants (Figure $1 B$ ).

The relative chlorophyll content, expressed as SPAD units, in tomato leaves was not significantly affected either by the Fe deficiency (F condition) or by the treatments with the protein hydrolysate ( $\mathrm{CB}$ and $\mathrm{FB}$ conditions), in comparison with the $\mathrm{C}$ condition (Figure $1 \mathrm{C}$ ).

Similarly to tomato plants, cucumber plants showed the same growth level at harvest (i.e., 17 days from sowing), independently from the nutrient supply and biostimulant application 
(C: control; CB: control supplied with the protein hydrolysate; F: Fe-deficient; and FB: Fe-deficient supplied with the protein hydrolysate, Figure 1D).
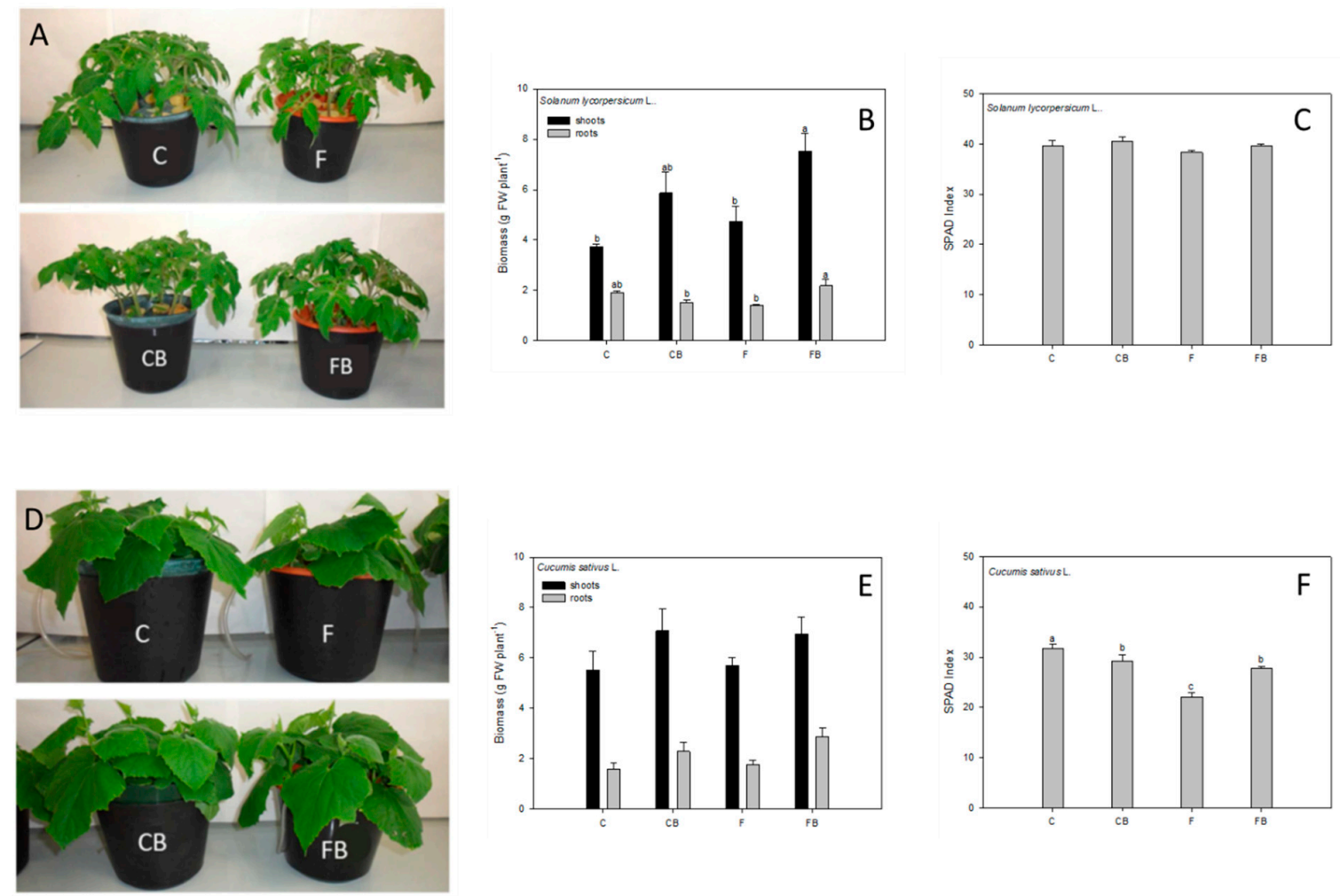

Figure 1. Growth parameters of 17-day-old tomato (Solanum lycopersicum L.) and 22-day-old cucumber (Cucumis sativus L.) plants grown in either a full nutrient solution supplied without or with the plant-derived protein hydrolysate ( $\mathrm{C}$ and $\mathrm{CB}$, respectively) or a Fe-deficient nutrient solution supplied without or with the plant-derived protein hydrolysate (F and FB, respectively): (A) representative tomato plants grown; (B) shoot and root biomass of tomato plants; (C) SPAD units of tomato plants; (D) representative cucumber plants; (E) shoot and root biomass of cucumber plants; (F) SPAD units of cucumber plants. Data are reported as means $\pm \mathrm{SE}(n=3)$. Statistical significance was tested by one-way ANOVA analysis with the Student-Newman-Keuls post hoc test $(p<0.001)$. Different letters indicate statistically different values within each plant species.

Differently from tomato plants, no significant effect was observed in terms of both shoot and root biomass accumulation in cucumber plants following imposition of Fe deficiency ( $F$ condition) or treatments with the protein hydrolysate (CB and FB conditions) (Figure 1E).

In addition, cucumber $\mathrm{F}$ plants showed evident chlorosis, corresponding to a $30 \%$ reduction in respect to $C$ plants (Figure 1F), but when Fe deficiency was combined with the protein hydrolysate treatment (FB condition), the reduction in relative chlorophyll content was only about $12 \%$ compared to $C$ plants and, more interestingly, the SPAD index of FB plants did not differ statistically from that of CB plants (Figure 1F).

\subsection{Effect of Growth Condition on Root Fe $e^{3+}$ Reductase Activity of Tomato and Cucumber Plants}

In tomato, root $\mathrm{Fe}^{3+}$ reduction activity was significantly induced $(+70 \%)$ by the $\mathrm{F}$ condition compared to the $\mathrm{C}$ condition. On the other hand, under treatment with the protein hydrolysate ( $\mathrm{CB}$ and $\mathrm{FB}$ conditions), tomato root reductase activity showed levels comparable to those of control C roots (CB and FB vs. C) (Figure 2A). 

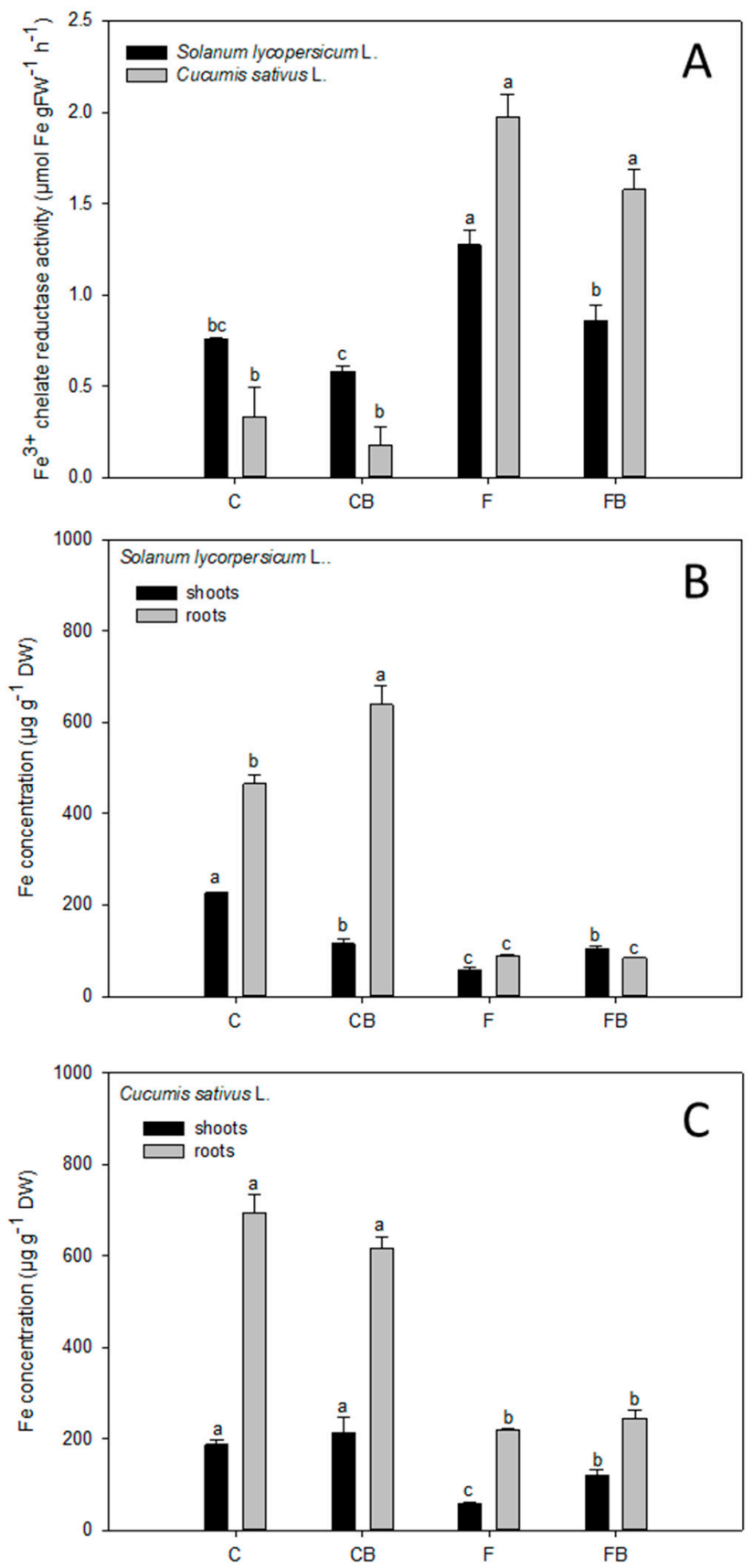

Figure 2. Iron $\left(\mathrm{Fe}^{3+}\right.$ )-chelate reductase activity (A) in tomato (Solanum lycopersicum L.) and cucumber (Cucumis sativus L.) plants grown in either a full nutrient solution supplied without or with the plant-derived protein hydrolysate ( $\mathrm{C}$ and $\mathrm{CB}$, respectively) or a Fe-deficient nutrient solution without or with the plant-derived protein hydrolysate (F and FB, respectively). Iron concentration of tomato (B) and cucumber (C) roots and shoots grown in either a full nutrient solution supplied without or with the plant-derived protein hydrolysate ( $\mathrm{C}$ and $\mathrm{CB}$, respectively) or a Fe-deficient nutrient solution without or with the plant-derived protein hydrolysate (F and FB, respectively). Data are presented as means $\pm \mathrm{SE}(n=3)$. Statistical significance was tested by one-way ANOVA analysis with the Student-Newman-Keuls post hoc test $(p<0.001)$. Different letters indicate statistically different values within each plant species.

Additionally, in cucumber, $\mathrm{Fe}^{3+}$-reducing capacity was stimulated by Fe deficiency, and a similar pattern was observed for the FB condition, with increases of almost five and four times, respectively, 
compared to the control C (Figure 2A). On the other hand, the treatment of control plants with the protein hydrolysate (CB condition) did not affect $\mathrm{Fe}^{3+}$ reductase activity (Figure 2A).

\subsection{Effect of Growth Condition on Fe Concentration of Tomato and Cucumber Plants}

The Fe concentration in Fe-deficient tomato shoots was significantly reduced by $70 \%$ in the $\mathrm{F}$ condition and by $50 \%$ when Fe-deficient plants were treated with the protein hydrolysate (FB condition) compared to that found in C shoots (Figure 2B). Interestingly, the Fe stored in FB shoot tissues was almost 2-fold higher than in F ones (Figure 2B). On the other hand, CB plants exhibited a lower (about $-50 \%$ ) capability to accumulate $\mathrm{Fe}$ at the shoot level with respect to $\mathrm{C}$ plants (Figure 2B).

In tomato roots, the limited Fe supply in the NS caused a significant decrease in Fe concentration in both F and FB root tissues, having about $80 \%$ less Fe than $\mathrm{C}$ roots (Figure 2B), whereas the application of the biostimulant to control plants (CB plants) increased the Fe concentration in the roots by $30 \%$ compared to $\mathrm{C}$ roots (Figure 2B).

Moreover, in cucumber, the reduced Fe availability in the NS significantly reduced the shoot Fe concentration, but the decrease was 70\% in F shoots and only $35 \%$ in FB shoots, compared to C shoots (Figure 2C). Thus, Fe accumulation in FB shoots was 2-fold higher than in F shoots (Figure 2C). Looking at control cucumber plants, the treatment with the protein hydrolysate did not affect the plants' capability to accumulate Fe at the shoot level (CB vs. C) (Figure 2C).

Further at the root level, $\mathrm{F}$ and FB plants had a significantly lower Fe concentration (-70\%) than $\mathrm{C}$ plant roots (Figure 2C), but the application of the biostimulant did not affect root Fe accumulation (i.e., FB vs F. and CB vs. C, Figure 2 C).

\subsection{Effect of Protein Hydrolysate on Nutritional Composition of Tomato Plants}

The principal component analysis (PCA), carried out on the dataset describing the concentration of mineral elements (such as $\mathrm{Ca}, \mathrm{Cu}, \mathrm{Fe}, \mathrm{K}, \mathrm{Mg}, \mathrm{Mn}, \mathrm{Mo}, \mathrm{Na}, \mathrm{P}, \mathrm{S}$ and $\mathrm{Zn}$ ) of tomato plant shoots, extracted 11 components with the following eigenvalues: 6.526, 2.143, 1.191, 0.597, 0.197, 0.180, 0.082, $0.043,0.035,0.005$ and 0.001 , respectively, which described $100 \%$ of the total variance (Figure $3 \mathrm{~A}$ ): the first two components, used to build the scatter plot, represented $78.81 \%$ of the total variance. The four different nutrient conditions (C, CB, F and FB) clustered in four distinct groups (Figure 3A); along the first component (PC1), which described $59.32 \%$ of the total variance, the different nutrient conditions were separated according to the different plant Fe availability in the nutrient solution (i.e., FB vs. $\mathrm{CB}$ and $\mathrm{F}$ vs. C), while along the second component (PC2), which described $19.48 \%$ of the total variance, the different nutrient conditions were separated as a function of the protein hydrolysate treatment (i.e., FB vs. F and CB vs. C) (Figure 3A). The positive contribution to the separation along PC1 was given by the content of mineral elements as follows: $\mathrm{Mg}>\mathrm{Ca}>\mathrm{Cu}>\mathrm{Mo}>\mathrm{Zn}>\mathrm{Mn}>\mathrm{P}>\mathrm{S}$, while Fe concentration was the variable which contributed most negatively, in addition to $\mathrm{K}$ and $\mathrm{Na}$, to the separation along PC1 (Figure 3A). Considering PC2, mostly K, Na and Fe concentrations drove the distribution along the positive direction of the axis, while only $\mathrm{Ca}$ and $\mathrm{Zn}$ concentrations were the drivers for the negative direction of the axis (Figure 3A).

When the PCA was applied to the dataset of the mineral element concentration of tomato roots, 11 components with eigenvalues of $4.188,3.052,1.880,0.900,0.484,0.219,0.116,0.096,0.045,0.014$ and 0.005 , respectively, were extracted and accounted for $100 \%$ of the total variance. The first two components described $65.82 \%$ of the total variance and the corresponding scatter plot is shown in Figure 3B. The PCA still clearly highlights the separation of the samples, deriving from the four different nutrient conditions (C, CB, F and FB), in four distinct clusters (Figure 3B): again, PC1 (38.07\% of the total variance) separated the different nutrient conditions according to the different plant Fe availability in the nutrient solution (i.e., CB vs. FB. and C vs. F), whereas PC2 (27.743\% of the total variance) separated the different nutrient conditions as a function of the protein hydrolysate treatment (i.e., $\mathrm{CB}$ vs. $\mathrm{C}$ and FB vs. F) (Figure 3B). Along PC1, the positive influence for the distribution was given by the following mineral elements: $\mathrm{Mn}>\mathrm{Fe}>\mathrm{K}>\mathrm{S}>\mathrm{Na}>\mathrm{Mo}>\mathrm{P}>\mathrm{Cu}>\mathrm{Ca}$, while the negative one was given 
primarily by $\mathrm{Mg}$ and, to a lesser extent, by Zn concentration (Figure 3B). Along PC2, the highest positive influence for the distribution by mineral element concentrations followed this order: Mo $>$ $\mathrm{Zn}>\mathrm{Na}>\mathrm{K}>\mathrm{Cu}>\mathrm{Mg}>\mathrm{S}$. On the other hand, the concentrations of $\mathrm{P}>\mathrm{Fe}>\mathrm{Mn}>\mathrm{Ca}$ were those variables which negatively influenced the distribution along PC2 (Figure 3B).
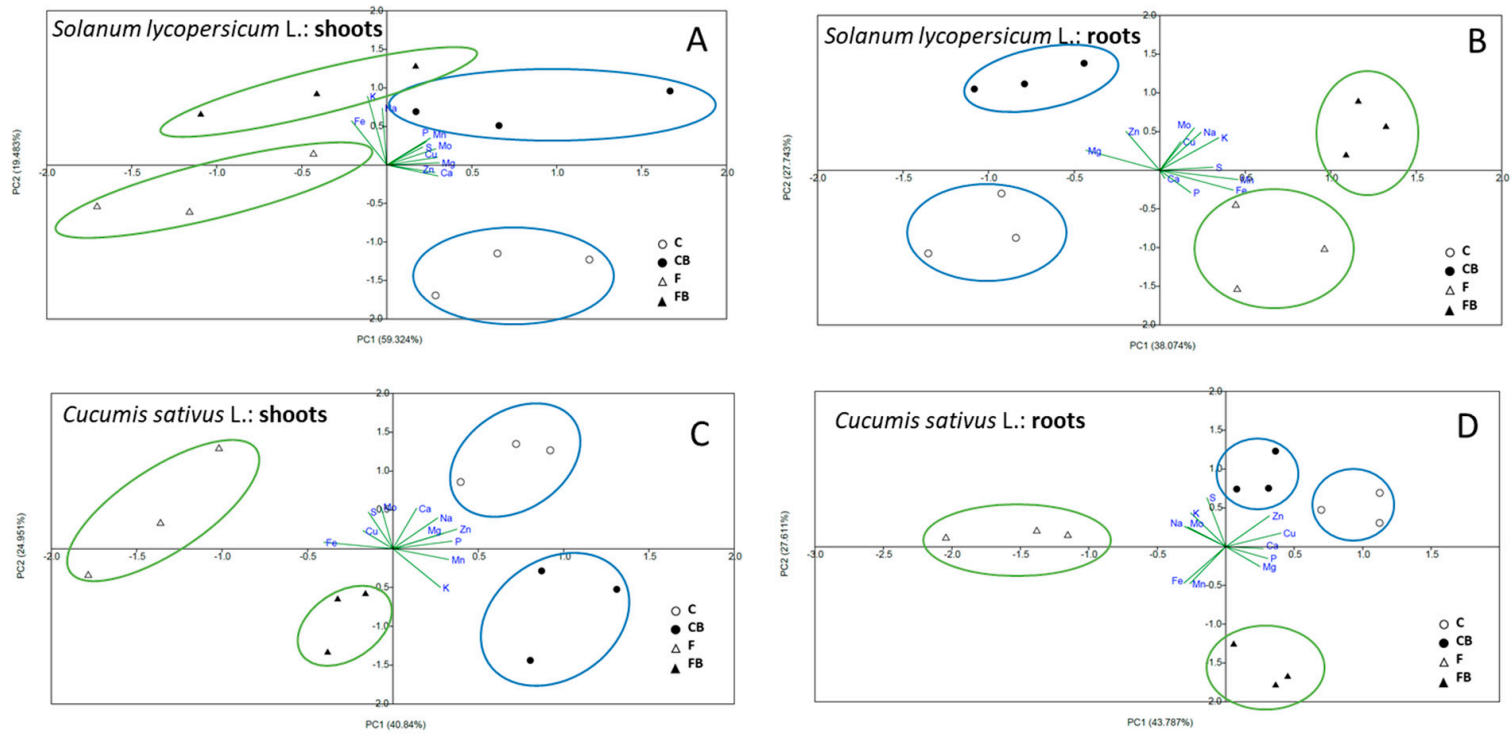

Figure 3. Principal component analysis of shoot and root ionome of tomato $(\mathbf{A}, \mathbf{B})$ and cucumber $(\mathbf{C}, \mathbf{D})$ plants. Empty symbols represent plants not supplemented with a plant protein-based hydrolysate biostimulant, while full symbols represent plants supplemented with a protein-based hydrolysate biostimulant. Plants were grown in either a full nutrient solution supplied without or with the plant-derived protein hydrolysate $(\mathrm{C}$ and $\mathrm{CB}$, respectively, both represented by the circles) or a Fe-deficient nutrient solution without or with the plant-derived protein hydrolysate ( $\mathrm{F}$ and $\mathrm{FB}$, respectively, both represented by the triangles).

Significant changes in macronutrient concentrations were induced (i) by the treatment with the protein hydrolysate, which resulted in a reduced accumulation of $\mathrm{K}$ (by $70 \%$ and $25 \%$ in shoots and roots, respectively), Mo (by 15\% and 25\% in shoots and roots, respectively), $\mathrm{Zn}$ (by $10 \%$ and $25 \%$ in shoots and roots, respectively) and S (40\% but only at the root level) (Table S1) and (ii) by the imposition of the Fe deficiency condition, which increased the Mg content and reduced the K content (Table S1). The concentrations of the other macronutrients, such as $\mathrm{Ca}, \mathrm{P}$ and $\mathrm{S}$, were not affected by any nutrient condition at both the shoot and root level (Table S1).

Among micronutrients, the Fe deficiency condition strongly increased $\mathrm{Cu}$ and $\mathrm{Zn}$ concentrations in shoots, while it reduced Mn concentration in roots with respect to control plants (Table S1). Sodium concentration was reduced by the protein hydrolysate treatment ( $-39 \% \mathrm{CB}$ vs. C and $-45 \% \mathrm{FB}$ vs. C) in roots and by combined biostimulant treatment and Fe deficiency ( $-30 \%$ FB vs. C) in shoots (Table S3).

\subsection{Effect of Growth Conditions on Nutritional Composition of Cucumber Plants}

The PCA, applied to the dataset of the mineral element concentrations (such as $\mathrm{Ca}, \mathrm{Cu}, \mathrm{Fe}, \mathrm{K}, \mathrm{Mg}$, $\mathrm{Mn}, \mathrm{Mo}, \mathrm{Na}, \mathrm{P}, \mathrm{S}$ and $\mathrm{Zn}$ ) of cucumber shoots, extracted 11 components with the following eigenvalues: $4.492,2.745,1.788,0.901,0.465,0.324,0.202,0.050,0.028,0.003$ and 0.001 , respectively, which accounted for $100 \%$ of the total variance. The scatter plot, obtained combining the first two principal components (i.e., $\mathrm{PC} 1$ and $\mathrm{PC} 2$ ), described $65.79 \%$ of the total variance and showed a distinct separation of the samples (C, CB, F and FB) in four distinct clusters (Figure 3C). Along PC1 (describing 40.84\% of the total variance), samples clustered according to the different plant Fe availabilities in the nutrient solution (i.e., $\mathrm{F}$ vs. $\mathrm{C}$ and $\mathrm{FB}$ vs. $\mathrm{CB}$ ), pointing out that mineral elements such as $\mathrm{Zn}>\mathrm{P}>\mathrm{Mn}>\mathrm{Mg}>\mathrm{K}>\mathrm{Na}$ $>\mathrm{Ca}$ were the stronger drivers for the positive direction of the axis and $\mathrm{Fe}>\mathrm{Cu}>\mathrm{S}>\mathrm{Mo}$ for the 
negative direction of the axis (Figure 3C). Along PC2 (describing $24.95 \%$ of the total variance), samples clustered as a function of the protein-based hydrolysate treatment (i.e., $\mathrm{F}$ vs. $\mathrm{FB}$ and $\mathrm{C}$ vs. $\mathrm{CB}$ ); mineral elements such as $\mathrm{Mo}>\mathrm{Ca}>\mathrm{S}>\mathrm{Na}>\mathrm{Zn}>\mathrm{Cu}>\mathrm{Mg}>\mathrm{P}>$ Fe resulted as the stronger drivers for the positive direction of the axis, while the distribution along the negative direction of the axis was driven mainly by the concentration of $\mathrm{K}$ and, to a lesser extent, by that of Mn (Figure 3C).

When the PCA was carried out on the dataset of the mineral element concentration of cucumber roots, 11 components with eigenvalues of $4.817,3.037,2.070,0.361,0.270,0.223,0.123,0.062,0.029$, 0.008 and 0.000 , respectively, were extracted and accounted for $100 \%$ of the total variance. The first two components described $71.398 \%$ of the total variance and the corresponding scatter plot is shown in Figure 3D. The PCA still identified the separation of the samples deriving from the four different nutrient conditions (C, CB, F and FB) in four distinct clusters (Figure 3D); however, in this case, PC1 (representing $43.79 \%$ of the total variance) separated Fe-deficient samples (F condition on the negative axis) from all others (F vs. CB, C and F), while PC2 (representing $27.61 \%$ of the total variance) separated Fe-deficient samples treated with the protein hydrolysate (FB condition on the negative axis) from all of the three other nutrient conditions (FB vs. CB, C and F) (Figure 3D). Along PC1, the positive influence for the distribution was driven by the following mineral elements: $\mathrm{Cu}>\mathrm{Zn}>\mathrm{P}>\mathrm{Ca}>\mathrm{Mg}$, while the negative one was driven by $\mathrm{Fe}>\mathrm{Na}>\mathrm{Mo}>\mathrm{Mn}>\mathrm{K}$ concentrations (Figure 3D). Along PC2, the highest positive influence for the distribution was given by the mineral element concentrations as follows: $\mathrm{S}>\mathrm{K}>\mathrm{Zn}>\mathrm{Na}>\mathrm{Mo}>\mathrm{Cu}$. On the other hand, the concentrations of $\mathrm{Mn}>\mathrm{Fe}>\mathrm{Mg}>\mathrm{P}>\mathrm{Ca}$ were those variables which negatively influenced the distribution along PC2 (Figure 3D).

In cucumber, as well as in tomato, the treatment with the biostimulant resulted in a reduction in K concentration (by 35\% in both tissues) and S concentration (by $20 \%$ and $40 \%$ in shoots and roots, respectively), but also a reduced accumulation of $\mathrm{S}$ at the root level $(60 \%)$ and Fe at the shoot level $(20 \%)$ (Table S2). On the other hand, we also detected an increase in the content of $\mathrm{Cu}$ and $\mathrm{Zn}$ at the root level (20\% in both cases) and of $S$ and Mo at the shoot level ( $25 \%$ and $60 \%$, respectively) (Table S2).

Among micronutrients, the imposition of Fe deficiency increased $\mathrm{Cu}$ concentrations only in roots and $\mathrm{Zn}$ accumulation in both roots and shoots, whereas it decreased the Mn content in roots compared to the controls (Table S2). On the other hand, the treatment with the protein hydrolysate increased Mo concentration at the shoot level with respect to control plants (Table S2). Only the F condition reduced Na concentration $(-42 \%)$ in the root tissues in respect to $C$ roots (Table S3). It is interesting to note that $\mathrm{CB}, \mathrm{F}$ and FB shoots had higher Na concentrations than $\mathrm{C}$ shoots and the highest increase percentage was observed when the protein hydrolysate treatment was combined with Fe deficiency $(+24 \% \mathrm{FB}$ vs. C, Table S3).

\section{Discussion}

The quali-quantitative improvement of primary productions is an important challenge considering the need to increase agricultural sustainability. In this respect, in recent years, the research interest toward the application of biostimulants has been clearly intensified. Among biostimulants, protein hydrolysates are particularly interesting for their demonstrated ability to modulate the molecular and physiological processes that promote plant growth, favor increased yield and alleviate the impact of abiotic stress on crops [21].

In this work, we investigated and characterized the effect of a legume-derived protein hydrolysate on the growth and development of tomato and cucumber plants. These two plant species were selected for their wide diffusion and economic relevance in the horticultural sector of the Mediterranean area. Furthermore, we evaluated the ability of this product to mitigate the effects of Fe shortage. Iron deficiency represents a critical issue in the life cycle of many crops, particularly in calcareous soils, which are the majority in the Mediterranean area.

The results here presented show that the application of the protein hydrolysates did not affect the growth rate of both tomato and cucumber plants adequately fed with all the nutrients (Figure 1B,E). Furthermore, no significant difference in relative chlorophyll content was found between tomato plants 
grown in the nutrient solution adequately supplied with all the nutrients $(C)$ and those supplied with the protein hydrolysates (CB). On the contrary, cucumber plants supplied with biostimulants exhibited lower relative chlorophyll contents than control plants (Figure 1C,F). However, the PCA analysis enabled the identification of significant changes induced by the supply of biostimulants. Indeed, the nutritional composition of both roots and shoots led to a clear separation of $C$ and CB samples in both species (Figure 3). In particular, data shown in both Tables S1 and S2 indicate that K accumulation was limited in plants exposed to the protein hydrolysates. In this respect, it is worth mentioning that $\mathrm{K}$ is a nutrient playing a crucial role in plant metabolism, being involved in the stomatal opening and closure, directly affecting plant photosynthetic capacity as well as the synthesis and, therefore, the source/sink allocation of carbohydrates [27]. Therefore, the drop in K content here recorded is very likely to cause an irregular ripening of tomato as well as a lower consistency of cucumber fruits, thus resulting in a poorer crop quality [28]. However, it is important to highlight that in both crops, the accumulation of $\mathrm{Ca}$, which could be important in the post-harvest phase [29], was not affected by the biostimulant supply (Tables S1 and S2).

On the other hand, in cucumber plants, the accumulation as well as the allocation at the shoot level of some essential nutrients resulted in being increased as a consequence of the root exposure to the protein hydrolysate. In particular, the $\mathrm{Cu}$ and $\mathrm{Zn}$ accumulation increased in $\mathrm{CB}$ plants, but only at the root level, whereas $S$ and Mo increased only at the shoot level, likely suggesting the occurrence of changes in the metabolic activity of plants. Indeed, it has been suggested that Mo can induce the synthesis of abscisic acid and nitric oxide, which are involved in the regulation of root system growth [30]. Thus, the different levels of Mo accumulated in cucumber plants (Table S2) could be functional to the improvement of the plants' ability to acquire water and nutrients, obtained through greater development of the root system, as suggested by the slight increase in root biomass accumulation in cucumber plants treated with the biostimulant (CB, Figure 1E).

The second working hypothesis of this work was that the protein hydrolysate could be able to improve plant capability to cope with Fe deficiency stress. The most common symptoms of Fe deficiency are leaf chlorosis and an increase in root biomass accumulation due to the development of numerous secondary roots [31-33]. In particular, Fe-deficient plants trigger the number and length of absorbent hairs [34] and the formation of "transfer" cells [35]. Measurements of plant growth parameters showed divergence in plant response to the application of biostimulants between the two selected species (Figure 1). For tomato, the root biomass of plants exposed to solely Fe deficiency stress appeared significantly reduced in comparison with control plants, whereas plants exposed to both Fe deficiency and biostimulant treatment (FB condition) reached values not significantly different from those exposed to the $C$ and $C B$ conditions (Figure 1B). On the contrary, in cucumber plants, no significant effects on plant growth were observed regardless of the nutrient supply or biostimulant application (Figure 1E).

The higher expansion of the root apparatus observed in tomato plants can be considered a general response of seedlings to Fe shortage, as previously described [36,37], and suggests a positive effect of the biostimulant. In addition, biostimulant treatment not only promoted the growth of plant roots, thus improving the stress tolerance of plants, but also stimulated the growth of the aerial part of the FB tomato plants which reached values two times greater than the control plants C (Figure 1B). Considering leaf chlorosis caused by Fe shortage, it has been observed that the drop in the relative chlorophyll content ( $-30 \%$ compared to control C) only occurred in cucumber plants (Figure $1 \mathrm{~F})$, but this response was minimized in FB plants (Fe-deficient but treated with the biostimulant) compared to $\mathrm{F}$ ones. It is interesting to note that FB plants showed a relative chlorophyll content that was not significantly different from that measured in the $\mathrm{CB}$ plants, grown in the presence of the optimal $\mathrm{Fe}$ concentration, and was only $5 \%$ lower than that determined in control plants $C$ (Figure 1F). Therefore, this effect could be ascribed to the biostimulant's ability to improve the plant's efficiency to face Fe deficiency stress. 
It is well known that dicots such as tomato and cucumber plants are characterized by a $\mathrm{Fe}^{3+}$ reduction-based mechanism for nutrient acquisition and rely on the enhancement of this activity to cope with Fe shortage [22]. As expected, the data presented here (Figure 2A) show exactly this behavior in plants exposed to the nutritional stress. However, when the Fe deficiency was associated with the supply of the biostimulant (FB condition), the extent of this enhancement was lower than that observed in the F condition (Figure 2A). This result could be explained by hypothesizing that in FB plants, the biostimulant application may have improved both uptake and accumulation of Fe and therefore enzyme activity was modulated by plant nutritional status (Fe concentration in shoot and root tissues), rather than by the availability of the nutrient in the growth medium. Indeed, the levels of Fe accumulated in shoots of both FB tomato and cucumber plants treated with the biostimulants seem to confirm this hypothesis (Figure 2B,C). Furthermore, it is interesting to note that Fe accumulation in FB tomato shoots was comparable to that recorded in the shoots of plants adequately fed with nutrients and supplied with the biostimulants (CB, Figure 2B).

Finally, the PCA analysis computed with the macro- and micronutrient concentrations in shoot and root tissues of the plants evidenced a clear separation of the four different nutritional conditions, suggesting that the biostimulant not only improves Fe accumulation by Fe-deficient plants, but also triggers an adjustment of the whole plant nutritional status (Figure 3). In particular, it is important to note that Fe shortage induced specific nutrient interactions in the plants regardless of the biostimulant supply. For instance, a synergistic $\mathrm{Cu} / \mathrm{Fe}$ and $\mathrm{Zn} / \mathrm{Fe}$ interaction was observed only in the shoots of tomato plants. On the other hand, cucumber plants revealed an enhanced Fe deficiency-induced $\mathrm{Cu}$ accumulation only in the roots and a synergistic $\mathrm{Zn} / \mathrm{Fe}$ effect on both shoots and roots (Tables S1 and S2). These results further corroborate the positive effect of biostimulants on plant performance (i.e., alleviating Fe stress) by increasing Fe concentration in plant tissues yet maintaining the Fe deficiency-induced synergistic effect of other essential micronutrients.

In conclusion, the results clearly show a limited effectiveness of this vegetal-derived protein hydrolysate when supplied to crops fed with an adequate availability of all the nutrients. On the other hand, its contribution to enhance plant performance in conditions of nutritional stress is of paramount importance, indicating a compensation effect. In fact, in an increasingly sustainable agriculture context, the possibility of having products/molecules capable of stimulating plants to grow and produce in non-optimal edaphic conditions and/or better exploiting the endogenous soil resources of nutrients is of particular value, also considering the environmental and economic benefits related to the limited need and, thus, application of fertilizers.

Supplementary Materials: The following are available online at http://www.mdpi.com/2073-4395/10/12/1942/s1, Table S1: Macro- and micronutrients concentrations in roots and shoots of tomato (Solanum lycopersicum L.) plants grown in either a full nutrient solution supplied without or with plant-derived protein hydrolysate $(C$ and $C B$, respectively) or a Fe-deficient nutrient solution supplied without or with plant-derived protein hydrolysate (F and FB, respectively). Data are reported as means \pm SE $(n=3)$. Statistical significance was tested by one-way ANOVA analysis with Student-Newman-Keuls post hoc test. Different superscript letters indicate statistically different values within each column $\left({ }^{*} p<0.05,{ }^{* *} p<0.01,{ }^{* * *} p<0.001\right)$, ns = not significant; Table S2: Macroand micronutrients concentrations in roots and shoots of cucumber (Cucumis sativus L.) plants grown in either a full nutrient solution supplied without or with plant-derived protein hydrolysate $(C$ and $C B$, respectively) or a Fe-deficient nutrient solution supplied without or with plant-derived protein hydrolysate (F and FB, respectively). Data are reported as means \pm SE $(n=3)$. Statistical significance was tested by one-way ANOVA analysis with Student-Newman-Keuls post hoc test. Different superscript letters indicate statistically different values within each column $\left({ }^{*} p<0.05,{ }^{* *} p<0.01,{ }^{* * *} p<0.001\right)$, ns $=$ not significant; Table S3: Sodium (Na) concentrations in roots and shoots of cucumber (Cucumis sativus L.) and tomato (Solanum lycopersicum L.) plants grown in either a full nutrient solution supplied without or with plant-derived protein hydrolysate $(\mathrm{C}$ and $\mathrm{CB}$, respectively) or a Fe-deficient nutrient solution supplied without or with plant-derived protein hydrolysate (F and FB, respectively). Data are reported as means \pm SE $(n=3)$. Statistical significance was tested by one-way ANOVA analysis with Student-Newman-Keuls post hoc test. Different superscript letters indicate statistically different values within each column $\left({ }^{*} p<0.05,{ }^{* *} p<0.01,{ }^{* * *} p<0.001\right)$. 
Author Contributions: S.A. and G.C. designed experiments and supervised the study. S.C. (Silvia Celletti) and N.G. performed sample preparation and experimental procedures. T.M. and S.C. (Silvia Celletti) executed data statistical analysis and data evaluation. S.A., T.M. and S.C. (Silvia Celletti) wrote the manuscript. S.A. and T.M. provided financial support to the study. All authors contributed to the analysis and interpretation of data. S.C. (Stefano Cesco) and G.C. critically revised the manuscript. All authors read, discussed and approved the final manuscript.

Funding: This research did not receive any specific grant from funding agencies in the public, commercial or not-for-profit sectors.

Acknowledgments: The research was carried out in the frame of the MIUR (Ministry for education, University and Research) initiative "Department of excellence" (Law 232/2016).

Conflicts of Interest: The authors declare no conflict of interest.

\section{References}

1. Kim, S.A.; Guerinot, M.L. Mining iron: Iron uptake and transport in plants. FEBS Lett. 2007, 581, $2273-2280$. [CrossRef] [PubMed]

2. Briat, J.-F. Mechanisms of iron homeostasis in plants and their regulations. In Proceedings of the International Plant Nutrition Colloquium XVI, Sacramento, CA, USA, 26-30 August 2009.

3. Briat, J.-F.; Curie, C.; Gaymard, F. Iron utilization and metabolism in plants. Curr. Opin. Plant Biol. 2007, 10, 276-282. [CrossRef] [PubMed]

4. Briat, J.-F.; Vert, G. Acquisition et gestion du fer par les plantes. Agriculture 2004, 13, 183-201.

5. Marschner, P. Mineral Nutrition of Higher Plants, 3rd ed.; Academic Press: London, UK, 2012.

6. López-Millán, A.F.; Duy, D.; Philippar, K. Chloroplast iron transport proteins-Function and impact on plant physiology. Front. Plant Sci. 2016, 7, 178. [CrossRef]

7. Morrissey, J.; Guerinot, M.L. Iron uptake and transport in plants: The good, the bad, and the ionome. Chem. Rev. 2009, 109, 4553-4567. [CrossRef]

8. FAO \& ITPS Status of the World's Soil Resources (SWSR)_Main Report; Food and Agriculture Organization of the United Nations and Intergovernmental Technical Panel on Soils: Rome, Italy, 2015; Available online: http://www.fao.org/3/a-i5199e.pdf (accessed on 10 October 2020).

9. Mengel, K. Iron availability in plant tissues-iron chlorosis on calcareous soils. Plant Soil 1994, 165, $275-283$. [CrossRef]

10. Nikolic, M.; Kastori, R. Effect of bicarbonate and Fe supply on Fe nutrition of grapevine. J. Plant Nutr. 2000, 23, 1619-1627. [CrossRef]

11. du Jardin, P. Plant biostimulants: Definition, concept, main categories and regulation. Sci. Hortic. 2015, 196, 3-14. [CrossRef]

12. Yakhin, O.I.; Lubyanov, A.A.; Yakhin, I.A.; Brown, P.H. Biostimulants in Plant Science: A Global Perspective. Front. Plant Sci. 2017, 7, 2049. [CrossRef]

13. Zanin, L.; Tomasi, N.; Cesco, S.; Varanini, Z.; Pinton, R. Humic Substances Contribute to Plant Iron Nutrition Acting as Chelators and Biostimulants. Front. Plant Sci. 2019, 10, 675. [CrossRef]

14. Zhang, X.; Schmidt, R.E. Hormone-Containing Products' Impact on Antioxidant Status of Tall Fescue and Creeping Bentgrass Subjected to Drought. Crop Sci. 2000, 40, 1344-1349. [CrossRef]

15. Calvo, P.; Nelson, L.; Kloepper, J.W. Agricultural uses of plant biostimulants. Plant Soil 2014, 383, 3-41. [CrossRef]

16. Colla, G.; Rouphael, Y.; Canaguier, R.; Svecova, E.; Cardarelli, M. Biostimulant action of a plant-derived protein hydrolysate produced through enzymatic hydrolysis. Front. Plant Sci. 2014, 5. [CrossRef]

17. Colla, G.; Nardi, S.; Cardarelli, M.; Ertani, A.; Lucini, L.; Canaguier, R.; Rouphael, Y. Protein hydrolysates as biostimulants in horticulture. Sci. Hortic. 2015, 196, 28-38. [CrossRef]

18. Peixoto, J.V.M.; Neto, C.; Campos, L.F.C.; Dourado, W.D.; Nogueira, A.P.O.; Nascimento, A.D. Industrial tomato lines: Morphological properties and productivity. Genet. Mol. Res. 2017, 16. [CrossRef]

19. Wang, M.; Liu, S.; Zhang, S.; Miao, H.; Tian, G.; Lu, H.; Liu, P.; Wang, Y.; Gu, X. QTL mapping of seedling traits in cucumber using recombinant inbred lines. Plant Breed. 2016, 135, 124-129. [CrossRef]

20. FAO. The State of Food and Agriculture; Food and Agriculture Organization of the United Nations: Rome, Italy, 2001. 
21. Colla, G.; Hoagland, L.; Ruzzi, M.; Cardarelli, M.; Bonini, P.; Canaguier, R.; Rouphael, Y. Biostimulant action of protein hydrolysates: Unraveling their effects on plant physiology and microbiome. Front. Plant Sci. 2017, 8, 2202. [CrossRef]

22. Kobayashi, T.; Nishizawa, N.K. Iron Uptake, Translocation, and Regulation in Higher Plants. Annu. Rev. Plant Biol. 2012, 63, 131-152. [CrossRef]

23. Zhang, F.S.; Römheld, V.; Marschner, H. Role of the root apoplasm for iron acquisition by wheat plants. Plant Physiol. 1991, 97, 1302-1305. [CrossRef]

24. Coppa, E.; Celletti, S.; Pii, Y.; Mimmo, T.; Cesco, S.; Astolfi, S. Revisiting Fe/S interplay in tomato: A split-root approach to study the systemic and local responses. Plant Sci. 2018, 276, 134-142. [CrossRef]

25. Dell'Orto, M.; Santi, S.; De Nisi, P.; Cesco, S.; Varanini, Z.; Zocchi, G.; Pinton, R. Development of Fe-deficiency responses in cucumber (Cucumis sativus L.) roots: Involvement of plasma membrane H+-ATPase activity. J. Exp. Bot. 2000, 51, 695-701. [CrossRef]

26. Vizzotto, G.; Pinton, R.; Bomben, C.; Cesco, S.; Varanini, Z.; Costa, G. Iron reduction in iron-stressed plants of Actinidia deliciosa genotypes: Involvement of PM Fe(III)-chelate reductase and H+-ATPase activity. J. Plant Nutr. 1999, 22, 479-488. [CrossRef]

27. Mengel, K.; Kirkby, E.A.; Kosegarten, H.; Appel, T. Plant nutrients. In Principles of Plant Nutrition; Springer: Dordrecht, The Netherlands, 2001; pp. 1-13.

28. Besford, R.T.; Maw, G.A. Effect of potassium nutrition on tomato plant growth and fruit development. Plant Soil 1975, 42, 395-412. [CrossRef]

29. Hernández-Pérez, O.I.; Valdez-Aguilar, L.A.; Alia-Tejacal, I.; Cartmill, A.D.; Cartmill, D.L. Tomato Fruit Yield, Quality, and Nutrient Status in Response to Potassium: Calcium Balance and Electrical Conductivity in the Nutrient Solution. J. Soil Sci. Plant Nutr. 2020, 20, 484-492. [CrossRef]

30. Wu, S.; Hu, C.; Tan, Q.; Zhao, X.; Xu, S.; Xia, Y.; Sun, X. Nitric oxide acts downstream of abscisic acid in molybdenum-induced oxidative tolerance in wheat. Plant Cell Rep. 2018, 37, 599-610. [CrossRef]

31. Pinton, R.; Cesco, S.; De Nobili, M.; Santi, S.; Varanini, Z. Water- and pyrophosphate-extractable humic substances fractions as a source of iron for Fe-deficient cucumber plants. Biol. Fertil. Soils 1997, 26, $23-27$. [CrossRef]

32. Zuchi, S.; Cesco, S.; Varanini, Z.; Pinton, R.; Astolfi, S. Sulphur deprivation limits Fe-deficiency responses in tomato plants. Planta 2009, 230, 85-94. [CrossRef]

33. Marschner, H.; Römheld, V.; Cakmak, I. Root-induced changes of nutrient availability in the rhizosphere. J. Plant Nutr. 1987, 10, 1175-1184. [CrossRef]

34. Schmidt, W.; Tittel, J.; Schikora, A. Role of hormones in the induction of iron deficiency responses in Arabidopsis roots. Plant Physiol. 2000, 122, 1109-1118. [CrossRef]

35. Schikora, A.; Schmidt, W. Iron stress-induced changes in root epidermal cell fate are regulated independently from physiological responses to low iron availability. Plant Physiol. 2001, 125, 1679-1687. [CrossRef]

36. Pestana, M.; De Varennes, A.; Abadía, J.; Faria, A. Differential tolerance to iron deficiency of citrus rootstocks grown in nutrient solution. Sci. Hortic. 2005. [CrossRef]

37. Jelali, N.; Salah, I.B.; M'sehli, W.; Donnini, S.; Zocchi, G.; Gharsalli, M. Comparison of three pea cultivars (Pisum sativum) regarding their responses to direct and bicarbonate-induced iron deficiency. Sci. Hortic. 2011, 129, 548-553. [CrossRef]

Publisher's Note: MDPI stays neutral with regard to jurisdictional claims in published maps and institutional affiliations.

(C) 2020 by the authors. Licensee MDPI, Basel, Switzerland. This article is an open access article distributed under the terms and conditions of the Creative Commons Attribution (CC BY) license (http://creativecommons.org/licenses/by/4.0/). 